\title{
Gossypol Inhibits Electron Transport and Stimulates ROS Generation in Yarrowia lipolytica Mitochondria
}

\author{
Anna Yu. Arinbasarova, Alexander G. Medentsev and Vladimir I. Krupyanko* \\ G.K. Skryabin Institute of Biochemistry and Physiology of Microorganisms, Russian Academy of Sciences, 142290, \\ Pushchino, Moscow Region, Pr. Nauki 5, Russia
}

\begin{abstract}
This work studied the effect of gossypol on the mitochondrial respiratory chain of Yarrowia lipolytica. The compound was shown to inhibit mitochondrial electron transfer and stimulate generation of reactive oxygen species. The inhibition kinetics in oxidation of various substrates (NADH, succinate, $\alpha$-glycerophosphate and pyruvate + malate) by isolated mitochondria was investigated. Analysis of the kinetic parameters showed gossypol to inhibit two fragments of the mitochondrial electron transfer chain: a) between coenzyme $Q$ and cytochrome $b$ with $K_{\text {IIIi }}$ of $118.3 \mu \mathrm{M}$ (inhibition by the noncompetitive type), and b) at the level of exogenous NADH dehydrogenase with $K_{\mathrm{Ii}}$ of $17.2 \mu \mathrm{M}$ (inhibition by the mixed type).
\end{abstract}

Keywords: Gossypol, ROS production, Kinetics of inhibition, Mitochondria, Yarrowia lipolytica.

\section{INTRODUCTION}

Gossypol, a triterpenoid aldehyde, is a naturally occurring compound extracted from the cotton plant and other plants of the genus Gossypium infected by phytopathogenic fungi [1]. The compound has been shown to reveal bacteriostatic [2], antifungal [3-5], antitumor [6,7], antifertility [8, 9] and anti-insect [10] activities. Being biologically active, gossypol has received significant attention as a potential medicinal product and has been extensively studied over the past two decades.

The biological activity of gossypol is mainly due to a disturbance of mitochondrial function, such as modification of the mitochondrial concentration of $\mathrm{Ca}^{2+}$, that associated with membrane fluidity [11], disruption of oxidative phosphorylation by inhibition of mitochondrial succinic dehydrogenase [12], release of cytochrome $c$ from mitochondria into the cytosol suggesting a mitochondrial-mediated apoptotic mechanism $[13,14]$. It is the diversity of mitochondrial dysfunctions that remains the problem of gossypol toxicity opened. The understanding of the mechanism of gossypol action on eukaryotic cells would raise a possibility of clinical implications.

This work studied the effect of gossypol on the mitochondrial respiratory chain of the fungus Yarrowia lipolytica. Kinetic peculiarities of inhibition and hydrogen peroxide formation were examined with regard to the spectrum and mechanism of gossypol action.

\footnotetext{
*Address correspondence to this author at the G.K. Skryabin Institute of Biochemistry and Physiology of Microorganisms, Russian Academy of Sciences, 142290, Pushchino, Moscow Region, Pr. Nauki 5, Russia; Tel: 7(495) 92574 48; Fax: 7(495) 95633 70;

E-mail: krupyanko@ibpm.pushchino.ru
}

\section{MATERIALS AND METHODS}

The strain Yarrowia lipolytica VKM-Y-2378 was provided by the All-Russian Collection of Microorganisms (Russian Academy of Sciences). Cells were grown at $29^{\circ} \mathrm{C}$ with constant shaking $(200 \mathrm{rpm})$ in $700-\mathrm{mL}$ flasks containing liquid Reader's medium (100 mL) supplemented with $0.2 \%$ yeast autolysate and Burkholder trace elements. Glucose $(1 \%)$ was used as a growth substrate.

Mitochondria were isolated from the cells by a previously described enzymatic method [15]. Protein concentration was determined by the biuret reagent.

The rate of oxygen uptake by mitochondria was measured at $21 \pm 1^{\circ} \mathrm{C}$ using the Clark-type platinum electrode in a medium $(2 \mathrm{ml})$ containing $0.6 \mathrm{M}$ mannitol, $20 \mathrm{mM}$ Trisphosphate buffer ( $\mathrm{pH}$ 7.0). The concentration of oxygen dissolved in the medium was taken to be $250 \mu \mathrm{M}$.

Succinate was added at a concentration of $10.0 \mathrm{mM} ; \alpha-$ glycerophosphate, at $10.0 \mathrm{mM}$; NADH, $1.0 \mathrm{mM}$; and pyruvate + malate $(\mathrm{Pyr}+\mathrm{Mal})$, at $5 \mathrm{mM}$ each. $\mathrm{Pyr}+\mathrm{Mal}$ were added simultaneously for generation of endogenous NADH. Ascorbate and $\mathrm{N}, \mathrm{N}, \mathrm{N}^{\prime}, \mathrm{N}^{\prime}$-tetramethyl-p-phenylenediamine dihydrochloride (TMPD) (Sigma, USA) were added at 3.0 $\mathrm{mM}$ and $0.25 \mathrm{mM}$, respectively.

All the experiments were carried out in the presence of a classical uncoupler carbonyl cyanide $m$-chlorophenylhydrazone (CCCP) $(10 \mu \mathrm{M}$, Sigma).

$\mathrm{H}_{2} \mathrm{O}_{2}$ production by mitochondria was detected by monitoring 2',7'-dichlorodihydrofluorescein diacetate (DCDHFDA) by a spectrofluorimeter (Hitachi MPF-4, Japan). The excitation and emission wavelengths were 480 and $520 \mathrm{~nm}$, respectively [16]. Mitochondria $(0.8 \mathrm{mg}$ protein $/ \mathrm{ml})$ were incubated in the reaction medium containing $0.6 \mathrm{M}$ mannitol, $20 \mathrm{mM}$ Tris-phosphate buffer ( $\mathrm{pH} 7.0), 10 \mu \mathrm{M} \mathrm{CCCP}$, 
$20 \mu \mathrm{M}$ DCDHF-DA and $5 \mu \mathrm{E}$ horseradish peroxidase. Pyr + Mal were added at a concentration of $5 \mathrm{mM}$ each; succinate, at $10 \mathrm{mM}$; antimycin A, $5 \mu \mathrm{M}$; gossypol, $250 \mu \mathrm{M}$.

Gossypol, 2,2'-bi(8-formyl-1,6,7-trihydroxy-5-isopropyl3-methylnaphthalene) (Sigma), was added to the reaction medium as a methanol solution. The final concentration of methanol was up to $2 \%$. No changes in the rate of oxygen uptake by mitochondria were observed at this methanol concentration. Sensitivity to the inhibitor was expressed as the percentage of inhibition of uncoupled mitochondria before addition of inhibitor, $n_{\mathrm{i}}=v_{\mathrm{i}} / v_{0} \cdot 100$.

The values of $I_{50}$ (the dose required to inhibit the enzyme activity by $50 \%$ ) were estimated by extrapolation from the titration curves.

The root-mean-square deviations at a fivefold determination were: $v, n_{\mathrm{i}}$ and $I_{50}= \pm 2.5 \% ; K_{\mathrm{m}}, V$ and $h= \pm 7.5 \%$; $K_{\mathrm{i}}= \pm 10 \%$, using the standard program SigmaPlot 10 (USA).

\section{RESULTS AND DISCUSSION}

The mode of gossypol action was investigated using the obligate aerobic fungus $Y$. lipolytica as a suitable model. This microorganism was taken because its mitochondrial respiratory chain usually has three sites of energy conservation similar to those in plant, fungal or animal cells. However, in contrast with animal mitochondria it contains external NADH : ubiguinone oxidoreductase in addition to complex I, as in plants $[17,18]$.

We found that endogenous respiration of whole cells noticeably decreases (by 95\%) after addition of gossypol (0.25 mM).

A depression of oxygen uptake by gossypol has been shown earlier in respiring yeast and mammalian cells, and antimitochondrial activity is explained by selective inhibition of mitochondrial protein synthesis [8]. The inhibitory action of gossypol on $\mathrm{O}_{2}$ uptake in human prostate cancer cells has been reported to be due to a disruption of oxidative phosphorylation by inhibition of mitochondrial succinic dehydrogenase [12].

To elucidate the inhibitory action of gossypol on electron transfer, we studied the oxidase activity of mitochondria in the presence of some exogenous substrates, including $\mathrm{NADH}$, succinate, $\alpha$-glycerophosphate, and piruvate + malate. The results are shown in Fig. (1). The maximum depressing effect of gossypol (95\%) was observed during the oxidation of NADH (curve 1), $I_{50}$ was equal to $30 \mu \mathrm{M}$. For other substrates, the calculated $I_{50}$ values were equivalent and amounted to $190-195 \mu \mathrm{M}$.

The data of Fig. 1 presented as a Dixon plot yielded a series of straight lines (Fig. 2). Three lines corresponding to three oxidized substrates (succinate, $\alpha$-glycerophosphate and $\mathrm{Pyr}+\mathrm{Mal}$ ) intersected in one common point (Fig. 2, curves $2-4)$, that is in accordance with the equality of $I_{50}$. Most likely, the inhibitor acts at the level of a common electron carrier in the respiratory chain, e.g., between ubiquinone and cytochrome oxidase, and its inhibitory action is independent of the type of oxidized substrate. These lines can be imag- ined to correspond to one substrate at different concentrations, i.e., electrons transferred from respective dehydrogenases to the respiratory chain (in accordance with the rates of oxygen uptake by mitochondria without any inhibitor) (Fig. 1).

It should be noted that the concentration of transferred electrons could not be expressed explicitly; and the equality of $I_{50}$ for three oxidized substrates (Fig. 1, curves 2-4) is approximate. Despite these weak points we think that the use of the Dixon plot to determine the inhibition parameters (Fig. 2) is admissible.

Intersection of three lines on the abscissa (Fig. 2) and approximation of the data shows that inhibition of electron transfer by gossypol can be assigned to either the catalytic ( III $\left._{\mathrm{i}}\right)$ type according to the parametric classification [19, 20] or to the noncompetitive type in compliance with the

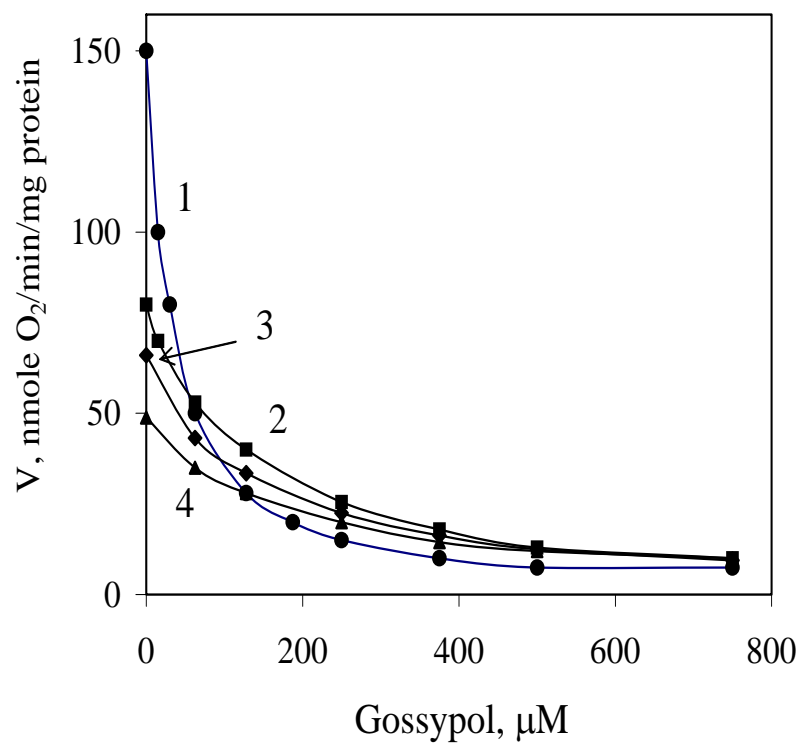

Fig. (1). Influence of gossypol concentrations on mitochondrial respiration in the presence of different exogenous substrates. 1, $\mathrm{NADH} ; 2, \alpha$-glycerophosphate; 3 , pyruvate + malate; 4 , succinate.

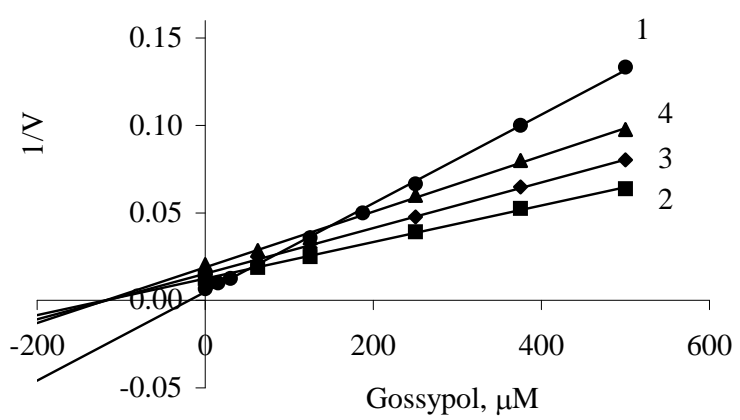

Fig. (2). Dixon plots of gossypol inhibition of oxygen consumption by mitochondria during oxidation of NADH (1), $\alpha$ glycerophosphate (2), pyruvate + malate (3) and succinate (4). Experimental values are taken from Fig. (1). 

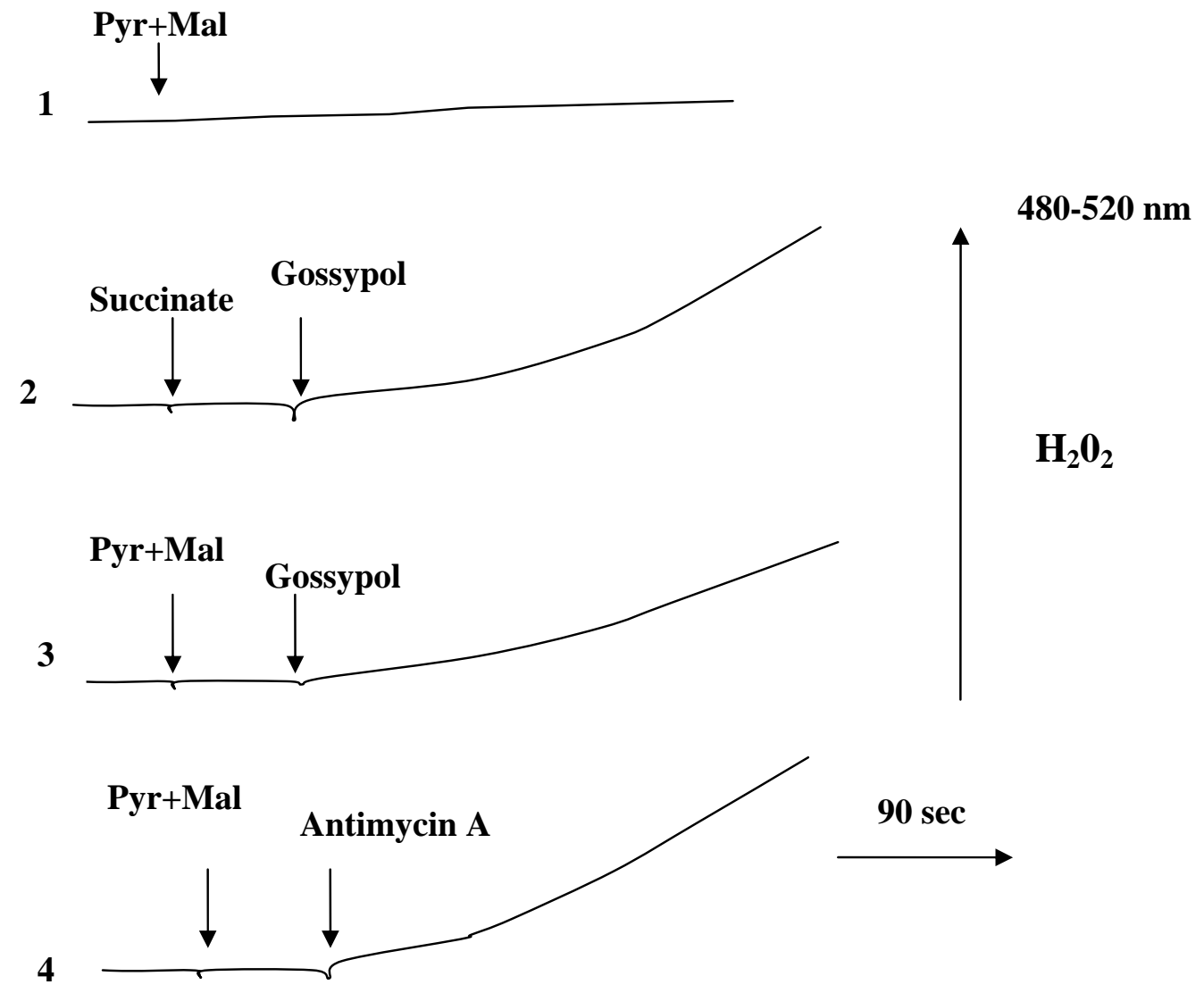

Fig. (3). Influence of gossypol on $\mathrm{H}_{2} \mathrm{O}_{2}$ generation by mitochondria. Mitochondria $(0.8 \mathrm{mg}$ protein/ml) were incubated in a reaction medium containing 0.6 M mannitol, $20 \mathrm{mM}$ Tris-phosphate buffer (pH 7.2), $10 \mu \mathrm{M}$ CCCP, $20 \mu \mathrm{M}$ DCDHF-DA and 5 U horseradish peroxidase. Pyruvate and malate were added at a concentration of $5 \mathrm{mM}$ each; succinate, $10 \mathrm{mM}$; antimycin A, $5 \mu \mathrm{M}$; gossypol, $250 \mu \mathrm{M}$.

traditional classification [20]. The kinetic parameters were determined to be

$$
K_{\mathrm{m}}^{\prime}=K_{\mathrm{m}(0.5)}^{0}, V^{\prime}<V^{0}, i>0,
$$

with $K_{\mathrm{IIIi}}$ of $118.3 \mu \mathrm{M}$ irrespective of substrate oxidized.

Our further investigation showed that oxidation of ascorbate as the respiratory substrate in the presence of TMPD was insensitive to gossypol but was inhibited by cyanide (95\%). From these results the gossypol coupling site is between coenzyme $Q$ and cytochrome $b$.

These findings suggest that reactive oxygen species (ROS), namely hydrogen peroxide, are produced. Fig. (3) shows representative traces of $\mathrm{H}_{2} \mathrm{O}_{2}$ production by mitochondria oxidizing succinate or pyruvate + malate. Addition of gossypol significantly increased the rate of $\mathrm{H}_{2} \mathrm{O}_{2}$ production (curves 2, 3). Antimycin A (a classical inhibitor of electron transfer at the level of cytochrome $b$ ) also increased the $\mathrm{H}_{2} \mathrm{O}_{2}$ production rate (curve 4 ). These results show that gossypol stimulates ROS production implying the ubiquinone pool in $\mathrm{H}_{2} \mathrm{O}_{2}$ generation.

On the other hand, gossypol, as shown earlier [13], does not increase the level of ROS and antioxidants and induces apoptosis in HL-60 cells through a ROS-independent mitochondrial dysfunction pathway. It has also been shown that gossypol activates genes responsible for the biosynthesis of antioxidant enzymes [6].

As can be seen from Fig. (2), the dependence of $1 / v$ versus gossypol concentration for exogenous NADH oxidation (curve 1) contrasted with that for the oxidation of the other substrates (curves 2-4), which suggests another peculiarity of inhibition. Obviously, there was the second site of gossypol binding the mitochondrial membrane, at the level of external NADH-dehydrogenase.

It has been shown earlier [21,22] that nucleotidemetabolizing enzymes are major targets for the action of gossypol in mammalian cells. Apparently, what we have here is the direct interaction of gossypol with the nucleotidebinding site of the enzyme, which provides a possible mechanism for the disturbance of normal cell function, namely, the disturbance of the balance between NADH and $\mathrm{NAD}+(\mathrm{NAD}+$ recycle $)$ in the cytosol.

The influence of gossypol on NADH oxidation (oxygen uptake) was tested to characterize the strength of gossypolexternal NADH dehydrogenase binding. The dependence of the initial rates of NADH oxidation by isolated mitochondria on NADH concentration in the absence (curve 1) and presence (curve 2) of gossypol $(30 \mu \mathrm{M})$ is given in Fig. (4). These curves were subjected to nonlinear extrapolation using a three-parameter Hill equation as described earlier [23]: 


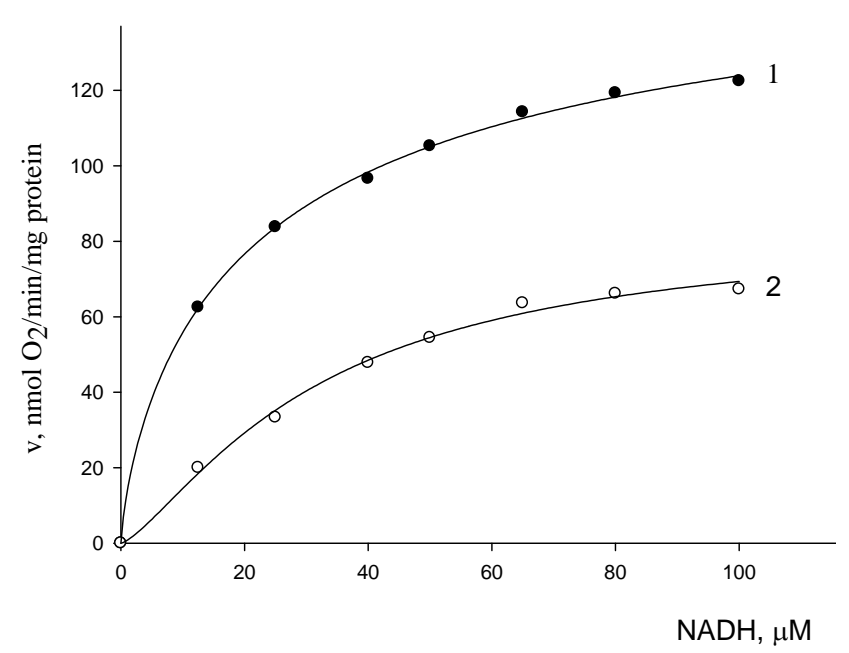

Fig. (4). Dependence of the initial reaction rates of oxygen uptake by mitochondria on NADH concentration in the absence (1) and presence (2) of gossypol $(30 \mu \mathrm{M})$.

$v=V^{0} \cdot \frac{\left(K_{\mathrm{m}}^{\prime}\right)^{h}}{\left(K_{\mathrm{m}}^{\prime}\right)^{h}+\left(K_{\mathrm{m} 0.5}^{0}\right)^{h}}$

The kinetic parameters of NADH oxidation were $V^{0}=$ $183.2 \mu \mathrm{mol} / \mathrm{min} \mu \mathrm{g}$ protein, $K_{\mathrm{m}(0.5)}^{0}=13.91 \mu \mathrm{M},\left(h^{0}=\right.$ 1.25 ) in the absence of gossypol (curve 1 ), and $V^{\prime}=84.06$ $\mu \mathrm{mol} / \mathrm{min} \mu \mathrm{g}$ protein, $\left(K_{\mathrm{m}}^{\prime}\right)^{h}=31.82 \mu \mathrm{M},\left(h^{\prime}=1.33\right)$ in the presence of gossypol (curve 2).

Based on the parametric classification of enzyme reaction types, the above data satisfied every attribute of biparametrically coordinated, $I_{i}$ (or mixed) type inhibition [21]:

$K_{m}^{\prime}>K_{m(0.5)}^{0}, V^{\prime}<V^{0}, i>0$

From these results, the enzyme exhibited a weak positive cooperativity by NADH and, moreover, the variation interval of the Hill coefficient $( \pm 6.5 \%)$ is within the framework of the calculation error. That allowed us to estimate the enzyme inhibition constant for gossypol $\left(K_{\mathrm{Ii}}\right)$, i.e., to determine the affinity of the inhibitor to the enzyme, using a modified equation [19]:

$$
\begin{aligned}
& K_{\mathrm{Ii}}=\frac{i}{\left[\left(\frac{K_{\mathrm{m}}^{\prime}-K_{\mathrm{m}(0.5)}^{0}}{K_{\mathrm{m}(0.5)}^{0}}\right)^{2}+\left(\frac{V^{0}-V^{\prime}}{V^{\prime}}\right)^{2}\right]^{0.5}}= \\
& \frac{30 \mu \mathrm{M}}{\left[\left(\frac{31.82-13.91}{13.91}\right)^{2}+\left(\frac{183.2-84.06}{84.06}\right)^{2}\right]^{0.5}}=17.2 \mu \mathrm{M}
\end{aligned}
$$

The data obtained demonstrate that gossypol has an affinity to the enzyme as the substrate oxidized does $\left(K_{\mathrm{Ii}} \cong\right.$
$\left.K_{\mathrm{m}(0.5)}^{0}\right)$, which makes enzyme-substrate binding difficult $\left(K_{\mathrm{m}}^{\prime}>K_{\mathrm{m}(0.5)}^{0}\right)$ and reduces the maximal reaction rate $\left(V^{\prime}\right.$ $\left.<V^{0}\right)$. The inhibition constant value calculated $\left(K_{\mathrm{Ii}}\right)$ is almost seven times lower than that for the other oxidized substrates $\left(K_{\text {IIIi }}\right)$.

\section{CONCLUSION}

In this work, we showed that gossypol inhibited the electron transfer in fungal mitochondria, which led to a disturbance of energy metabolism. The proposed kinetic approach enabled us to determine that gossypol inhibited two fragments of the mitochondrial electron transfer chain with different intensity: between coenzyme $Q$ and cytochrome $b$, with $K_{\mathrm{IIIi}}$ equal to $118.3 \mu \mathrm{M}$; and at the level of exogenous NADH dehydrogenase, with $K_{\mathrm{Ii}}$ equal to $17.2 \mu \mathrm{M}$. We also showed that inhibition of yeast cell respiration led to increase the concentration of ROS toxic for the cells.

The toxic effect of gossypol has been earlier observed in fungi: gossypol inhibited the growth of plant pathogens Fusarium decemcellulare [3], F. oxysporum [4] and Rhizoctonia solani [5]. From our results, the toxicity of gossypol for fungi can be also explained by the antimitochondrial effect: inhibition of cell respiration as well as stimulation of ROS generation.

As mentioned above, there are many modes of gossypol action in mitochondria; it is true, though, that this effect has been studied mainly in mammalian cells. It is the antimitochondrial properties of gossypol that can be the basis of its use as promising therapeutics (as an antifertility, anticancer, antiviral and/or antipathogenic agent) with great potential in clinical practice.

These data is a supplement to a variety of mechanisms of gossypol action in mitochondria and can be of interest for the debate on the interrelations between phytopathogens, plants and animals including humans.

\section{ABBREVIATION}

TMPD $=\mathrm{N}, \mathrm{N}, \mathrm{N}^{\prime}, \mathrm{N}^{\prime}$-tetramethyl-p-phenylenediamine dihydrochloride

$\mathrm{CCCP}=$ Carbonyl cyanide $m$-chlorophenylhydrazone

DCDHF-DA $=$ Dichlorodihydrofluorescein diacetate

ROS $=$ Reactive oxygen species

\section{ACKNOWLEDGEMENTS}

None declared.

\section{CONFLICT OF INTEREST}

None declared. 


\section{REFERENCES}

[1] Bell, A. Formation of gossypol in infected or chemically irritated tissues of Gossypium species. Phytopathology, 1967, 57, 759-764.

[2] Yildirim-Aksoy, M.; Lim, C.; Dowd, M. K.; Wan, P. J.; Klesius, P. H.; Shoemaker, C. In vitro inhibitory effect of gossypol from gossypol-acetic acid (+)-and (-)-isomers of gossypol on the growth of Edwardsiella ictaluri. J. Appl. Microbiol., 2004, 97, 87-92.

[3] Medentsev, A.; Akimenko, V. Effect of secondary metabolites and electron transfer inhibitors on napthoquinone synthesis in Fusarium decemcellulare. Microbiologiya, 1997, 66, 773-778 (Rus).

[4] Turco, E.; Vizzuso, C.; Franceschini, S.; Ragazzi, A.; Stefanini, F. $M$. The in vitro effect of gossypol and its interaction with salts on conidial germination and viability of Fusarium oxysporum sp. vasinfectum isolates. J. Appl. Microbiol., 2007, 103, 2370-2381.

[5] Puckhaber, L.; Dowd, M.; Stipanovic, R.; Howell, C. Toxicity of $(+)-$ and (-) -gossypol to the plant pathogen Rhizoctonia solani. $J$. Agric. Food Chem., 2002, 24, 7017-7021.

[6] Moon, D. O.; Choi, Y. H.; Moon, S. K.; Kim, W. J.; Kim, G. Y. Gossypol decreases tumor necrosis factor- $\alpha$-induced intercellular adhesion molecule-1 expression via suppression of NF- $\mathrm{kB}$ activity. Food Chem. Toxicol., 2011, 49, 999-1005.

[7] Volate, S.; Kawasaki, B. T.; Hurt, E. M.; Milnes, J.A.; Kim, Y.S., White, J.; Farrar, W. L. Gossypol induces apoptosis by activating p53 in prostate cancer cells and prostate tumor-initiating cells. Mol. Cancer Ther., 2010, 9, 461-470.

[8] Bugeja, V.; Charles, G.; Collier, D.; Wilkie, D. Primary mitochondrial activity of gossypol in yeast and mammalian cells. Biochem. Pharmcol.,1988, 37, 4217-4224.

[9] Dodou, K.; Anderson, R. J.; Small, D. A.; Groundwater, P. W. Investigations on gossypol: past and present developments. Expert Opin. Investig. Drugs, 2005, 14, 1419-34.

[10] Stipanovic, R.; Lopez, J.; Dowd, M., Puckhaber, L.; Duke, S. Effect of racemic and $(+)-$ and $(-)$ gossypol on the survival and development of Helicoverpa zea Larvae. J. Chem. Ecol., 2006, 32, 959-968.

[11] Martinez, F.; Milan, R.; Espinosa-Garcia, T.; Pardo, J. P. The antifertility agent, gossypol, releases calcium from rat liver mitochondria. Comp. Biochem. Physiol., 1993, 104, 165-169.

[12] Jiang, J.; Ghosh, P.; Kulp, S.; Sugimoto, Y.; Liu, S.; Czekajewski, J.; Chang, H.; Lin, Y. Effect of gossypol on $\mathrm{CO} 2$ consumption and
$\mathrm{CO} 2$ production in human prostate cancer cells. Anticancer Res., 2002, 22, 1491-1496.

[13] Hou, D. X.; Uto, T.; Tong, X.; Takeshita, T.; Tanigawa, S.; Imamura, I.; Ose, T.; Fujii, M. Involvement of reactive oxygen speciesindependent mitochondrial pathway in gossypol-induced apoptosis. Arch. Biochem. Biophys., 2004, 428, 179-187.

[14] Oliver, C. L.; Miranda, M. B.; Shangary, S.; Land, S.; Wang, S. Johnson, D., E. (-)-Gossypol acts directly on the mitochondria to overcome Bcl-2- and Bcl-X(L)-mediated apoptosis resistance. Mol. Cancer. Ther., 2005, 4, 23-31.

[15] Akimenko, V.; Medentsev, A.; Golovchenko, N. Isolation and some properties of mitochondria from yeast Candida lipolytica 695. Biokhimiya (Rus). 1975, 40, 395-400

[16] Black, M. J.; Brandt, R. B. Spectrofluorometric analysis of hydrogen peroxide. Anal. Biochem., 1974, 58, 246-254.

[17] Von Jagov, G.; Klingenberg, M. Pathway of hydrogen in mitochondria of Saccharomyces cerevisiae. Biochem. , J. 1970, 124, 853-865.

[18] Kerscher, S. J.; Okun J. G.; Brandt, U. A single external enzyme confers alternative NADH:ubiquinone oxidoreductase activity in Yarrowia lipolytica. J. Cell Science, 1999, 112, 2347-2354.

[19] Krupyanko, V. I. Corrected equations for calculation of constants in enzyme inhibition and activation. Biochemistry (Moscow), 2007, 72, 308-391.

[20] Krupyanko, V. I. Perspectives of data analysis of enzyme inhibition and activation. Part 2: Parametrical classification of types of enzymatic reactions. J. Biochem. Mol. Toxicol., 2009, 23, 191-107.

[21] Olgiati, K. L.; Hoffer, A. P.; Toscano, W. A. Gossypol modulation of nucleotide metabolizing enzymes in the reproductive tract of male rats. Biol. Reprod., 1984, 31: 759-770.

[22] Roberts, A. G.; Diaz, M. D.; Lampe, J. N.; Shireman, L. M.; Grinstead J. S.; Dabrowsky M. J.; Pearson J. T.; Bowman M. K.; Atkins W. M.; Campbell A. P. NMR Studies of Ligand Binding to P450eryF Provides Insight into the Mechanism of Cooperativity. Biochemistry, 2006, 45, 1673-1684

[23] Krupyanko, V. I. Additional Possibility of Data Analysis of Enzyme Inhibition and Activation. 8. A Choice of thr Equations for Calculation of Initial Rates vi and va in Enzyme Inhibition an Activation. J. Biol. Sci., 2007, 7, 506-513. 